\title{
Adherence to insulin self administration and associated factors among diabetes mellitus patients at Tikur Anbessa specialized hospital
}

\author{
Yusuf Gerada1*, Zuriyash Mengistu², Asrat Demessie², Atsede Fantahun ${ }^{3}$ and Kahsu Gebrekirstos ${ }^{3}$
}

\begin{abstract}
Background: The goals of diabetes treatment are to keep blood glucose levels as near normal as possible while avoiding complications. Despite the benefits of insulin therapy, many people with diabetes don't adhere to treatment. Some avoid insulin therapy or refuse to start it. Several studies investigating adherence to chronic disease treatment have evidenced that patients often discontinue their medications or even do not take them at all because they consider them ineffective or experience untoward side effects. To assess adherence to insulin self administration and associated factors among adult patients with diabetes mellitus at endocrinology unit of Tikur Anbessa Specialized Hospital Addis Ababa Ethiopia.
\end{abstract}

Methods: A cross-sectional study was conducted from December to June 2015, on a total of 378 diabetic patients on insulin self administration using convenience sampling method. The data was collected using structured questionnaires after ethical approval and informed signed consent have been taken. The data entry and analysis was conducted using Epi info version 3.5.4 and SPSS version 21.

Results: One hundred twenty five (33.1\%) of the respondents were found to be non-adherent to insulin self injection. Multivariate analysis identified who stopped taking insulin when they feel better, who have Heart disease and those not taking insulin when they were out of home for long time as independent factors for non adherence of insulin self administration.

Conclusion: The factors associated with non adherence to insulin self administrations were; forgetting time of injection, deliberately, feeling better and feeling worse.

Keywords: Adherence, Insulin self administration, Diabetes mellitus

\section{Background}

Diabetes mellitus (DM) is defined as a group of metabolic diseases characterized by hyperglycemia (increased blood glucose level) resulting from defects in insulin secretion, insulin action, or both [1]. Globally Diabetes becomes a significantly growing health problem and it is also an important problem in Africa. It is chronic disease that needs long term medical care and follow-up to prevent complications associated with the diseases [2]. Chronic

\footnotetext{
* Correspondence: yusufgerada08@gmail.com

${ }^{1}$ Addis Ababa University, Tikur Anbessa Specialized Hospital, Addis Ababa,

Ethiopia

Full list of author information is available at the end of the article
}

hyperglycemia is associated with long-term damage and failure of different organs of the body, especially the eyes, kidney, nerves, heart and blood vessels [3]. The patients with DM are also at a high risk of acute complications like hypoglycemia [4]. Adherence to treatment significantly influences the prevention and control of acute and longterm complications of DM [5]. Low cost strategies that can reduce the impact of diabetes and associated complications are: lifestyle modifications, physical activity and effective use of medication [6].

The goal of diabetes treatment is mainly to control blood glucose levels as near normal as possible with minimal complications [7]. In contrary to the benefits 
of insulin therapy, significant number of patients with diabetes show low adheres to treatment and some patients avoid insulin therapy or not willing to start it [8]. Several studies about chronic disease treatment have showed that patients discontinue their medications or even do not take them at all because they perceive that they are ineffective with untoward side effects [9-11]. Recent reports from World health organization (WHO) shows alarming magnitude of non-adherence and its long term complications, therefore it is very important improving adherence to existing treatments than developing new treatment modalities [1]. In developing countries effective insulin administration to manage hyper glycaemia remains challenging [12]. In most developing countries like Ethiopia, insulin is commonly available as single or multiple subcutaneous doses every day and the commonly used insulin injection devices are insulin syringes and pens. Insulin therapy remains unacceptable amongst patients with DM because of different reasons like needle phobia, expenses and inconvenience of the daily injections [12].

Even though different factors can affect treatment adherence, it is remains difficult to identify the main factors associated with treatment adherence. First, access of patients to drugs needs due consideration to rule out possibility of inaccessibility of the drugs [13]. Factors that associated with patient adherence to drug therapy can be grouped as follows: patient-related; patient-provider relationship, therapeutic regimen, and the disease itself [13]. Primary prevention of risk factors and secondary prevention of adverse health outcomes are some of the interventions that can help to improve adherence which in turn positive outcomes on the health condition of patients [14].

To improve patient adherence, it is important to understand the extent of patient adherence and why nonadherence to insulin self administration occurs. Even though there are studies conducted in different parts of the world, there is no enough studies conducted in the study area. Therefore, the objective of this study was to assess the pattern of adherence to insulin self administration and associated factors among adult patients with diabetes mellitus at endocrinology unit of Tikur Anbessa Specialized Hospital Addis Ababa Ethiopia.

\section{Methods}

The study was conducted from December to June, 2014 at Endocrinology unit of Tikur Anbessa Specialized Hospital, Addis Ababa City which is the main tertiary referral teaching and research Hospital in Ethiopia. Hospital based cross-sectional study design was used to conduct this study. The inclusion criteria was: having diabetes either type 1 or type 2 , non-pregnant, aged at least 18 years attending the diabetic clinic during the study period, taking insulin by themselves and giving written informed consent to participate in the study. Convenient sampling technique was used to Select 378 patients with DM who meet the mentioned inclusion criteria. The sample size was calculated using single population proportion formula $\left(\mathrm{n}=(\mathrm{Z} \alpha / 2)^{2} \mathrm{p}(1-\mathrm{p}) / \mathrm{d}^{2}\right)$. Data was collected using interviewer administered structured questionnaire which was developed from different literatures. The questionnaire was pretested in $10 \%$ of the sample size in different institution which was not included in the study to assess the validity and reliability. Non-adherence was assessed using patients self reports of how they had been taking their; Patients were asked to recall if they missed any doses of medication on a day by day basis over a period of one month. The number of injection missed was calculated based on the prescribed dose. Patients who reported taking less than $80 \%$ of their prescribed insulin injection was considered as non adherent to treatment. Clarity and completeness of the filled questionnaire was checked daily during the data collection period. Data was entered to Epi-info version 3.5.4 and exported to SPSS version 21.0, then cleared and analyzed. Descriptive statistics was computed to show frequency, percentage distribution, mean, median, range and standard deviation. Appropriate statistical techniques for data analysis was applied to determine association (OR and/or chi-square). Statistical significance was evaluated at $95 \%$ level of significance and the result was presented in the form of tables and pie chart.

\section{Results}

\section{Socio demographics characteristics}

A total of 378 respondents participated in this study with response rate of $100 \%$. Majority of the respondents were found to be at the age category of between 31and 55 years which accounts 195(51.6\%), the minimum and the maximum age of respondents was 19 and 78 years old respectively. One hundred ninety three (51.1\%) participants were males and $343((90.7 \%)$ of the respondents were urban residents. Two hundred sixty one $(69.0 \%)$ of participants were married and Orthodox in religion. Regarding educational status, 136(36.0\%) were in Secondary education [9-12], as well as 126(33.3\%) patients had monthly income of 500-1000 Birr (Table 1).

\section{Diabetes history}

About half 186 (49.3\%) of participants' duration of living with diabetic was greater than 10 years. One hundred seventy three 173 (45.8\%) of patients started insulin self administration therapy since 5-10 years. About 366 (96.8\%) clients used insulin syringe for self injection. Almost all (97.4\%) of participants' injection schedule of insulin was twice a day. One hundred ninety five (51.6\%) participants have been using one needle for 2-6 days 
Table 1 Socio-demographic distribution of insulin self administration diabetes patients in Endocrinology unit of TASH $2014(n=378)$

\begin{tabular}{|c|c|c|c|}
\hline Variables & & Frequency & Percent \\
\hline \multirow[t]{3}{*}{ Age } & $\leq 30$ & 109 & 28.8 \\
\hline & $31-55$ & 195 & 51.6 \\
\hline & $56-80$ & 74 & 19.6 \\
\hline \multirow[t]{2}{*}{ Sex } & Male & 193 & 51.1 \\
\hline & Female & 185 & 48.9 \\
\hline \multirow[t]{2}{*}{ Residence } & Urban & 343 & 90.7 \\
\hline & Rural & 35 & 9.3 \\
\hline \multirow[t]{5}{*}{ Ethnicity } & Amhara & 147 & 38.9 \\
\hline & Oromo & 97 & 25.7 \\
\hline & Guraghe & 59 & 15.6 \\
\hline & Tigre & 40 & 10.6 \\
\hline & Others & 35 & 9.3 \\
\hline \multirow[t]{4}{*}{ Marital status } & Married & 261 & 69.0 \\
\hline & Single & 75 & 19.8 \\
\hline & Widowed & 20 & 5.3 \\
\hline & Others (divorced, cohabitation) & 22 & 5.8 \\
\hline \multirow[t]{5}{*}{ Religion } & Orthodox & 248 & 65.6 \\
\hline & Muslim & 82 & 21.7 \\
\hline & Protestant & 34 & 9.0 \\
\hline & Catholic & 8 & 2.1 \\
\hline & $\begin{array}{l}\text { Others (pagan, Johba and } \\
\text { Wakefata) }\end{array}$ & 6 & 1.6 \\
\hline \multirow{4}{*}{$\begin{array}{l}\text { Level of } \\
\text { education }\end{array}$} & No formal education & 32 & 8.5 \\
\hline & Primary education [1-8] & 108 & 28.6 \\
\hline & Secondary education [9-12] & 136 & 36.0 \\
\hline & Diploma and above & 102 & 27.0 \\
\hline \multirow[t]{7}{*}{ Occupation } & Business/Self employed & 124 & 32.8 \\
\hline & Government employee & 86 & 22.8 \\
\hline & Housewife & 68 & 18 \\
\hline & NGO/Private sector employee & 29 & 7.7 \\
\hline & Student & 22 & 5.8 \\
\hline & Farmer & 19 & 5.0 \\
\hline & Others $^{a}$ & 30 & 7.9 \\
\hline \multirow[t]{4}{*}{ Monthly income } & $<500$ & 110 & 29.1 \\
\hline & $500-1000$ & 135 & 35.7 \\
\hline & $>1000$ & 126 & 33.3 \\
\hline & Unknown & 7 & 1.9 \\
\hline
\end{tabular}

${ }^{\mathrm{a}}$ Daily workers, retired

and only $4(1.1 \%)$ of participants have been using single needle once as recommended. More than half 261 (69.0\%) of patients visited to health care provider once every 6 months, only 17 (4.5\%) visits health care provider once a month. Two hundred fifty seven $(68.0 \%)$ of patients provided insulin freely from the Tkur Anbesa Specialized Hospital endocrinology unit. All most all of 371 (98.1\%) had regular follow up of DM clinic (Table 2).

\section{Practice of insulin self administration}

Almost all (99.2\%) respondents diagnosed as having DM for the first time by physicians. One third (33.07\%) of the respondents are found to be non-adherent to insulin injection (Fig. 1). only one in every 10 participants took his/her insulin injections at the same time daily as recommended while 347 (91.8\%) did not take insulin on similar time daily. Only 31 (8.2\%) participants did

Table 2 Distribution of diabetes patient by duration with diabetic and insulin self administration in TASH, 2014

\begin{tabular}{|c|c|c|c|}
\hline Variable & & Frequency & Percent (\%) \\
\hline \multirow{3}{*}{$\begin{array}{l}\text { Duration with } \\
\text { Diabetes Mellitus }\end{array}$} & $<10$ (Below median) & 136 & 36 \\
\hline & 10 (Median duration) & 56 & 14.8 \\
\hline & >10 (Above median) & 186 & 49.3 \\
\hline \multirow{3}{*}{$\begin{array}{l}\text { Duration of insulin } \\
\text { therapy (self administration) }\end{array}$} & $1-4$ years & 107 & 28.3 \\
\hline & $5-10$ years & 173 & 45.8 \\
\hline & $\geq 11$ years & 98 & 25.9 \\
\hline \multirow[t]{3}{*}{ Type of insulin device } & Insulin syringe & 366 & 96.8 \\
\hline & Insulin pen & 8 & 2.1 \\
\hline & $\begin{array}{l}\text { Needle with separate } \\
\text { syringe }\end{array}$ & 4 & 1.1 \\
\hline \multirow[t]{3}{*}{ Dosing schedule of insulin } & Once a day & 7 & 1.9 \\
\hline & twice a day & 368 & 97.4 \\
\hline & $\begin{array}{l}\text { more than } 2 \text { times per } \\
\text { day }\end{array}$ & 3 & 0.8 \\
\hline \multirow[t]{4}{*}{ Duration of needle use } & Once & 4 & 1.1 \\
\hline & One day & 6 & 1.6 \\
\hline & 2-6 days & 195 & 51.6 \\
\hline & 7 or more days & 173 & 45.8 \\
\hline \multirow[t]{2}{*}{ Regular follow up } & Yes & 371 & 98.1 \\
\hline & No & 7 & 1.9 \\
\hline \multirow{3}{*}{$\begin{array}{l}\text { Duration of visit to } \\
\text { health care provider }\end{array}$} & Once in a month & 17 & 4.5 \\
\hline & Once in 3 month & 100 & 26.5 \\
\hline & Once in 6 month & 261 & 69.0 \\
\hline \multirow[t]{2}{*}{ Source of insulin } & Free & 257 & 68.0 \\
\hline & Purchase & 121 & 32.0 \\
\hline \multirow[t]{2}{*}{ Cost of insulin } & Costly & 374 & 98.9 \\
\hline & Cheap & 4 & 1.1 \\
\hline \multirow{5}{*}{$\begin{array}{l}\text { Chronic condition(s) } \\
\text { patient have }\end{array}$} & Hypertension & 164 & 43.4 \\
\hline & Heart diseases & 60 & 15.9 \\
\hline & High cholesterol & 58 & 15.3 \\
\hline & Lung disease & 8 & 2.1 \\
\hline & Others diseases & 31 & 8.2 \\
\hline
\end{tabular}

${ }^{\mathrm{a}}$ More than one answer was given 


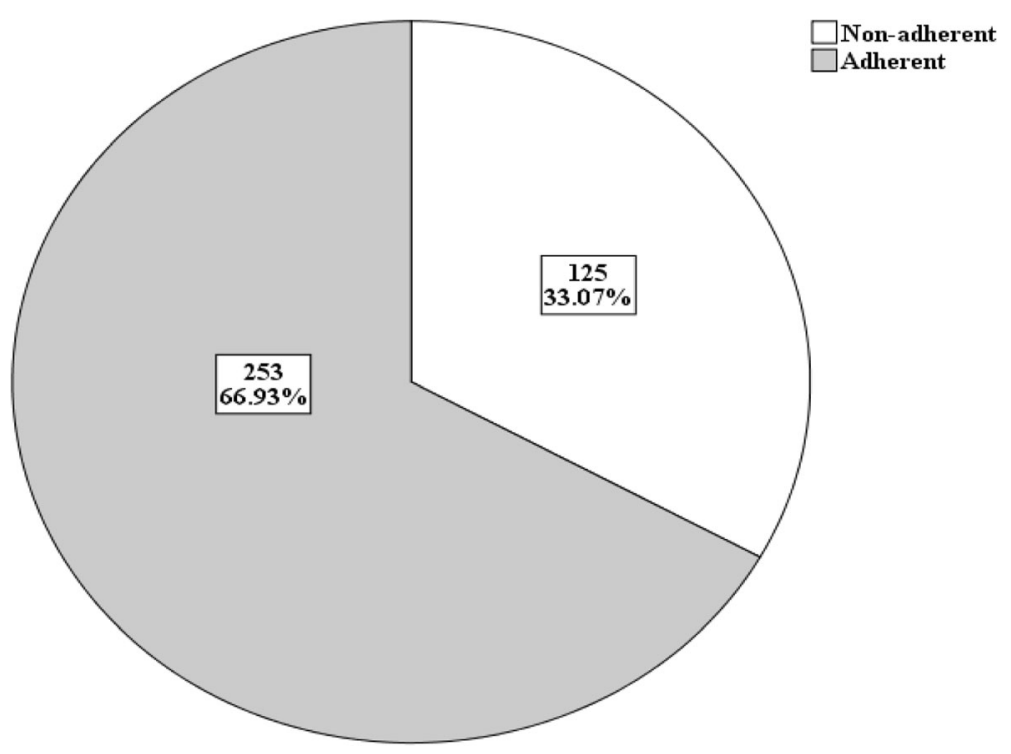

Fig. 1 Distribution of diabetes patients by adherence and non adherence to insulin self administration in TASH in endocrinology 2014. $(n=378)$

have ever missed doses of their insulin for some reasons; among these difficulty to afford the cost of insulin 4. (1.1\%) and due to nature of their work/schedule of work $15(4.0 \%)$. Twenty six (6.9\%) of participants stopped taking their medication when they were feeling better. Two hundred sixty three (69.6\%) were using abdomen as site of injection and 276(73.0\%) used upper arm. About $65.1 \%$ Respondents store/keep their insulin in refrigerator. About three fourth (75.7\%) of participant took their insulin with themselves when they were out of home for long time.

\section{Factors associated with insulin self administration}

Multivariate regression analysis identified the factors associated with adherence to insulin self administration: those who stopped taking insulin when they feel better, those who have Heart disease and those taking insulin when they were out of home for long time (Tables 3 and 4).

\section{Discussion}

This study tried to identify the factors associated with non adherence to insulin self administration. About 26 (6.9\%) of respondents stopped taking their medication during better feeling and 12 (3.2\%) during worse feeling. This finding is similar with study done in French [15]. In this study about $96.8 \%$ participants use insulin syringe and the rest use insulin pen and needle with separate syringe. This was higher as compared to a study conducted in India which showed $68.1 \%$ patients used Insulin syringes [16]. This difference might be due to time gap and the availability of insulin syringes.

In this study among about $64.3 \%$ respondents were developed adverse effects like lipohypertrophy at injection site. Whereas in a study conducted in Spain found that lipohypertrophy at injection sites complained by $29 \%$ patients [17]. This might be due lack of awareness and practice about injection site rotation. In this study $69.6 \%$ of respondents were commonly used abdomen and $86 \%$ upper thigh as injection site. In study conducted in Spanish Similarly abdomen and thigh of the participants had used as common injection sites [17].

In this study The factors associated with non adherence to insulin self administration were feeling better, pt developed heart disease and pt went out of home for long time. Where us in a study done in Tehran, Iran,

Table 3 The crude odd ratio (COR) that predict adherence to insulin self administration of diabetes patients in Endocrinology unit of TASH $2014(n=378)$

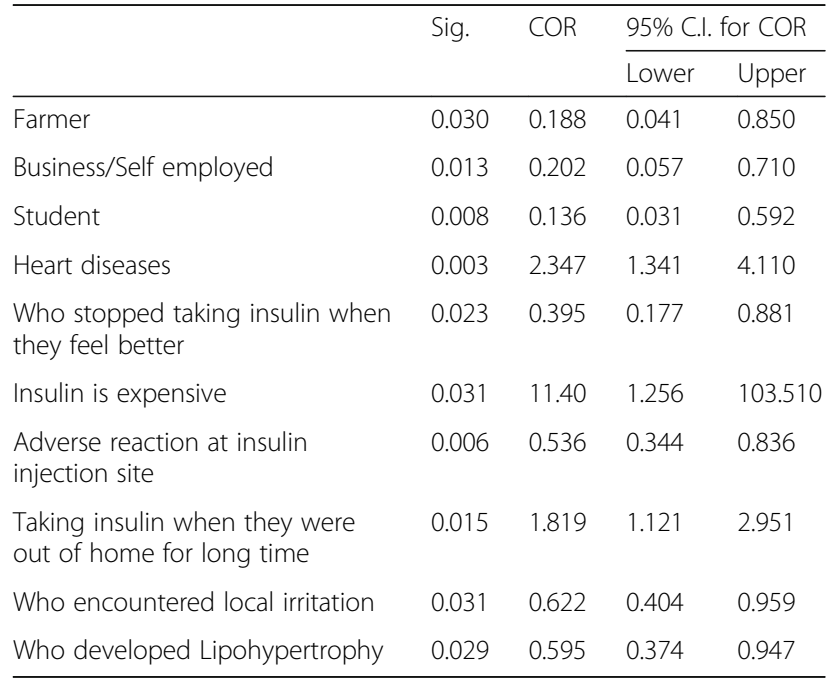


Table 4 The adjusted odd ratio (AOR) that predict adherence to insulin self administration of diabetes patients in Endocrinology unit of TASH 2014 ( $n=378)$

\begin{tabular}{|c|c|c|c|c|}
\hline \multirow{2}{*}{$\begin{array}{l}\text { Ever missed taking insulin } \\
\text { injection }\end{array}$} & \multirow[t]{2}{*}{ Sig. } & \multirow[t]{2}{*}{ AOR } & \multicolumn{2}{|c|}{$95 \% \mathrm{Cl}$ for $\mathrm{AOR}$} \\
\hline & & & Lower & Upper \\
\hline Intercept & 0.001 & & & \\
\hline Occupation & 0.246 & 1.068 & .956 & 1.194 \\
\hline Who have Heart disease & $0.001 *$ & 2.647 & 1.470 & 4.766 \\
\hline $\begin{array}{l}\text { Who stopped taking insulin when } \\
\text { they feel better }\end{array}$ & $0.005^{*}$ & 3.309 & 1.423 & 7.698 \\
\hline $\begin{array}{l}\text { Adverse reaction at } \\
\text { injection site }\end{array}$ & 0.050 & 1.663 & 1.001 & 2.765 \\
\hline $\begin{array}{l}\text { Taking insulin when they were } \\
\text { out of home for long time }\end{array}$ & $0.031^{*}$ & 0.565 & .336 & .948 \\
\hline Who encountered local irritation & 0.789 & 0.927 & .533 & 1.614 \\
\hline Who developed Lipohypertrophy & 0.104 & 1.577 & .911 & 2.729 \\
\hline
\end{tabular}

*Level of significance $\leq 0.05$

Factors that showed a significant association with insulin compliance were: being a time consuming process; embarrassment; feeling worse after injections; forgetfulness; sick days; experience of hypoglycemia; medication cost; weight gain; insulin shortage; and difficulties in preparing injection [18]. This difference might be because of variations in patient's awareness, analysis methods and study design.

In a study done in south India on the other hand, factors such as illiteracy, economic problems to buy medications, lack of information on prescribed medications, lack of awareness on the importance of regular medications, not visiting physician regularly and not following advice on diet are the major ones affecting non-adherence [19]. This variation might be due to difference in health care delivery system of the two countries.

In a study conducted in Adama Referral hospital, Ethiopia the factors associated with non adherence were reported as patient related such as (forgetfulness, intentional omission of dose) and drug related (cost, side effects, and multiple drug therapy especially in those with comorbidity) [20]. This difference might be due difference in Sociodemographic characteristics of respondents.

\section{Limitations}

- The study was mainly quantitative cross sectional, it cannot assess other possible factors of non adherence than those mentioned in literatures

- The study area was only Addis Ababa, this make difficult to generalize at community level

\section{Conclusion}

Based on the findings of this study, the following points concluded:
- One third of the respondents were found to be non-adherent to insulin injection. This is significant number which needs intervention to minimize the immediate and late complications associated with non adherence to insulin. So, ministry of health and significant others are recommended to act to minimize the non adherence level

- The factors associated with non adherence of insulin self administration were feeling better, pt developed heart disease and pt went out of home for long time as. These factors can be minimized through continuous monitoring and patient education by health professionals working in Endocrinology unit.

\section{Abbreviations \\ AOR: Adjust odds ratio; COR: Crude odds ratio; DM: Diabetes Mellitus; IDDM: Insulin Dependent Diabetes Mellitus; ISA: Insulin Self Administration; NGOs: Non-Governmental Organizations; NIDDM: Non-Insulin Dependent Diabetes Mellitus; SPSS: Statistical Package for Social Sciences; TASH: Tikur Anbasa Specialized Hospital; UKPDS: United Kingdom Prospective Diabetes Study; WHO: World Health Organization}

\section{Acknowledgements}

Our deepest gratitude will go to Addis Ababa University, College of health sciences, department of nursing. Our appreciation goes also to all those who help us throughout the study. Finally we want to thank to the study participants.

\section{Funding \\ The authors declare that no funding source for this study.}

\section{Availability of data and materials}

The data is presented in the main manuscript.

\section{Authors' contributions}

YG was the principal author of this research; he prepared the main parts of the paper. ZM and AD were the advisors of this study; they participated in reviewing and commenting the paper. AF and KG participated in preparation of manuscript and reviewing and commenting. All authors read and approved the final manuscript.

\section{Ethics approval and consent to participate}

Ethical approval was obtained from the institutional review board of Addis Ababa University College of health science department of nursing and midwifery. Permission was obtained from endocrinology unit of Tikur Anbessa Hospital. All respondents were informed about the objective of the study and their free choice to participate or withdraw whenever they wished during data collection period.

\section{Consent for publication}

Not applicable.

\section{Competing interests}

The authors declare that they have no competing interests.

\section{Publisher's Note}

Springer Nature remains neutral with regard to jurisdictional claims in published maps and institutional affiliations.

\section{Author details}

${ }^{1}$ Addis Ababa University, Tikur Anbessa Specialized Hospital, Addis Ababa, Ethiopia. ${ }^{2}$ Department of Nursing, College of Health Sciences, Addis Ababa University, Addis Ababa, Ethiopia. ${ }^{3}$ Department of Nursing, College of Health Sciences, Mekelle University, Mekelle, Ethiopia. 
Received: 11 October 2016 Accepted: 26 June 2017

\section{Published online: 01 July 2017}

\section{References}

1. American Diabetes Association (2010), Diagnosis and Classification of Diabetes Mellitus. Diab Care. 2010; 33(1):S62-S69).

2. Rwegerera, Mutashambara G. (2010). Adherence to Antidiabetic drugs and associated factors among patients with diabetes type 2 in Dar Es Salam. A master's dissertation (Internal Medicine) University of Muhimbili, Tanzania.

3. Balkau B, Eschwege E. The diagnosis and classification of diabetes mellitus and impaired glucose regulation. In pickup JC, Williams G, editors.Textbook of Diabetes. Oxford: Blackwell Science. 2003;2003:2.1-2.13.

4. Cryer PE. (2002) Hypoglycaemia the limiting factor in the glycaemic management of type I and type || diabetes. Diabetologia. 2002;45(7):937-48. [PubMed]

5. Toljamo M, Hentinen M. (2001), Adherence to self-care and glycaemic control among people with insulin-dependent diabetes mellitus. J Adv Nurs. 2001;34(6):780-6. [PubMed]

6. Diamond J. (2003)The double puzzle of diabetes. Nature 2003 June 5;423 (6940).

7. American Diabetes Association (2011) Standards of medical care in diabetes. Diab Care. 2011;34(Suppl 1):S11-S61. [PMC free article] [PubMed]).

8. Kellie Antinori-Lent. (2013). Improving insulin adherence in diabetes care. American Nurse Today.

9. Donnan PT, et al. Adherence to prescribed oral hypoglycemic medication in a population of patients with type 2 diabetes: a retrospective cohort study. Diabet Med 2002. 2002;19(4):279-84.

10. Leite SN. Vasconcellos MPC. Adesão à terapêutica medicamentosa: elementos para adiscussão de conceitos e pressupostos adotados na literatura. Ciênc Saúde Coletiva 2003. 2003;8(3):775-82.

11. Grant RW, Devita NG, Singer DE, Meigs JB. Polypharmacy and medication adherence in patients with type 2 diabetes. Diabetes Care 2003. 2003;26(5):1408-12.

12. Anthonia O Ogbera, Sonny F Kuku. (2012), Insulin use, prescription patterns, regimens and costs.-a narrative from a developing country. Diabetology \& Metabolic Syndrome 2012, 4:50 doi:10.1186/1758-5996-4-50).

13. Gimenes HT, Zanetti ML, Haas VJ. Factors related to patient adherence to antidiabetic to drug therapy. Rev Latinoam Enfermagem 2009 janeirofevereiro. 2009;17(1):46-51.

14. World Health Organization. Adherence to long term therapies, time for action. Geneva: World Health Organization; 2003.

15. Tiv M, Viel J-F, Mauny F, Eschwège E, Weill A, et al. Medication Adherence in type 2 diabetes: the ENTRED study 2007, a French population-based study. PLoS One. 2012;7(3):e32412. doi:10.1371/journal.pone.0032412).

16. Raina A. Etnal. (2010) knowledge, attitude and practice on disposal of sharp waste, used for home management of type 2 diabetes mellitus in New Delhi. India.

17. Hasen B, et al. Evidence-based clinical guidelines for injection of insulin for adultswith diabetes mellitus clinical nursing specialist: Arhus University Hospital in Spanish; 2012

18. Shadi Farsaei, Mania Radfar, Zahra Heydari, Farzaneh Abbasi, Mostafa Qorbani. Insulin adherence in patients with diabetes: Risk factors for injection omission. Primary care diabetes:2014.

19. Divya $S^{*}$, Pratibha Nadig. Factors Contributing To Non-Adherence To Medication Among Type 2 Diabetes Mellitus In Patients Attending Tertiary Care Hospital In South India. Asian J Pharm Clin Res, 8, 2, 2015, 274-276.

20. Gelaw BK, Abdela M, Tegegne GT, Defersha AD, Muluneh F, et al. Nonadherence and Contributing Factors among Ambulatory Patients with Antidiabetic Medications in Adama Referral Hospital. Hindawi Pub Corpo Diab Res. 2014; http://dx.doi.org/10.1155/2014/617041

\section{Submit your next manuscript to BioMed Central and we will help you at every step:}

- We accept pre-submission inquiries

- Our selector tool helps you to find the most relevant journal

- We provide round the clock customer support

- Convenient online submission

- Thorough peer review

- Inclusion in PubMed and all major indexing services

- Maximum visibility for your research

Submit your manuscript at www.biomedcentral.com/submit
C Biomed Central 